\title{
Design of an Embedded Engineering Learning on Social Cloud Model to Enhance Creative Thinking and Creative Product
}

\author{
https://doi.org/10.3991/ijoe.v13i01.5987 \\ Sathaporn Yoosomboon \\ King Mongkut's University of Technology North Bangkok \\ sataporn007@ hotmail.com \\ Pallop Piriyasurawong \\ King Mongkut's University of Technology North Bangkok \\ palloppi@gmail.com
}

\begin{abstract}
This study was conducted to research and develop an Embedded Engineering Learning on Social Cloud Model (EEL on SC Model) to enhance creative thinking and creative production. The aims of this study were 1) to design an EEL on SC Model to develop creative thinking and creative production and 2) to evaluate an EEL on SC Model. The research method was divided into two phases. The first phase involved the design of the model: 1) to study, analyze, and synthesize the content; 2) to arrange the Embedded Engineering Learning Model process; and 3) to summarize the results. The second phase involved the model evaluation. The sample group in this research consisted of seven experts in the fields of design embedded systems information technology and instructional design. These experts were selected by purposive sampling. Data were analyzed using arithmetic means and standard deviations. The process of developing an EEL on SC Model has 7 components that have 22 procedures. The model helps to develop creative thinking and creative production of the learners. The experts agreed with the overall model and had a learning activity that was appropriate at a very good level.
\end{abstract}

Key Words-Embedded System, Social Cloud, Creative Thinking, Creative Product, Imagineering

\section{Introduction}

The software industry has grown and improved continuously, especially, in the Embedded Software and Services industry, which has embedded systems, an important technology that helps to develop electronic, automobile devices, etc. to satisfy a variety of needs in our daily life, including to make it more convenient and safer [9]. Because 
of the previous point of view, it has caused many countries to implement policies that continuously support the development of embedded systems. Thailand is one of these countries that sees the necessity for this system. Thus, it has developed The Eleventh National Economic and Social Development Plan (2012-2016). This plan points out the necessities for developing Thailand's industries in the concept of Creative Economy by training crews to be able to satisfy the needs of production and management fields in both specialization and entrepreneurial levels to have Creative Thinking [8]. The Eleventh National Economic and Social Development Plan (2012-2016) is related to Thailand's ICT Policy Framework (B.E. 2554-2563, ICT 2020) Strategy 2: ICT human resources and an ICT competent workforce. Hence, Thailand established the Software Industry Promotion Agency, known as SIPA; in 2546 to support the development of 5 software industries. The embedded system industry is one of them. Statistics of SIPA in 2557 have shown how important these industries are in Thailand, but there is a problem with the lack of embedded system crews, especially in the embedded program development field, which has $51 \%$ of the total industries [12]. This has caused SIPA to implement a policy that supports the improvement of software crews' abilities to satisfy the needs of software managers in software industries like the embedded systems industry. Furthermore, this problem also forces educational institutes to improve crews, especially in engineering sectors. This causes the universities to manage their curriculum to help improve engineering students increase their practical skills to the level requested by the managers in the industries, especially in the embedded systems industry.

Embedded System is an important process for developing practical inventions and innovations. Embedded System is a programmable or fixed in capability device is controlled by a computer or the combination of computer hardware and software remodeled for a specific purpose. The possible hosts of an embedded system are medical equipment, industrial machines, airplanes, automobiles, household appliances, vending machines, cameras and toys [1], [10], [6], [15].

Imagineering is the fusion of the words "Engineering" and "Imagine" [4], which is the perfect mix of teaching method and the nature of learning, according to Walt Disney's theory [17]. This study developed the skills to fulfill the design and product development. In other words, Imagineering is the combination of imagination and engineering that helps learners recognize solutions for their problems by using their existing knowledge [2]. Imagineers are innovators, story tellers and magic creators. This process is about freeing the imagination, not being restricted by what you think you cannot accomplish and discovering what you can reach. Imagineers are the process of letting your imagination fly and then engineering it down to the ground. By blending imagination and engineering, dreamers and technicians discover how something works [7].

Social Cloud, the resource and service sharing framework using the relationships between members of a social network, creates the online co-working process that is characteristic of many social-specialized electronic platforms. Additionally, Social Cloud is a scalable computing model to which users contribute essential resources that are dynamically prepared among a group of collaborators. These resources may be shared usefully and freely [3], [13], [5].

Thus, the researcher decided to design an Embedded Engineering Learning on Social Cloud model to enhance

Creative Thinking and Creative Production of the learners. A conceptual framework of a teaching model was organized, and the suitability of the learning activities was 
Paper-Design of an Embedded Engineering Learning on Social Cloud Model to Enhance Creative Thinking and Creative Product

examined. The procedures in this model were the ways to create devices to support the teaching and learning for the students to use them efficiently.

\section{$2 \quad$ Research Objectives}

The purposes of this study were:

1. To design an Embedded Engineering Learning on Social Cloud model to enhance Creative Thinking and Creative Production.

2. To evaluate an Embedded Engineering Learning on Social Cloud model to enhance Creative Thinking and Creative Production.

\section{Conceptual Framework}

The conceptual framework of this research integrated four components in the design of the learning model. The components are the Embedded System, Imagineering, Collaborative (Jigsaw), and Social Cloud to develop the creative thinking and creative production as shown in Figure 1.

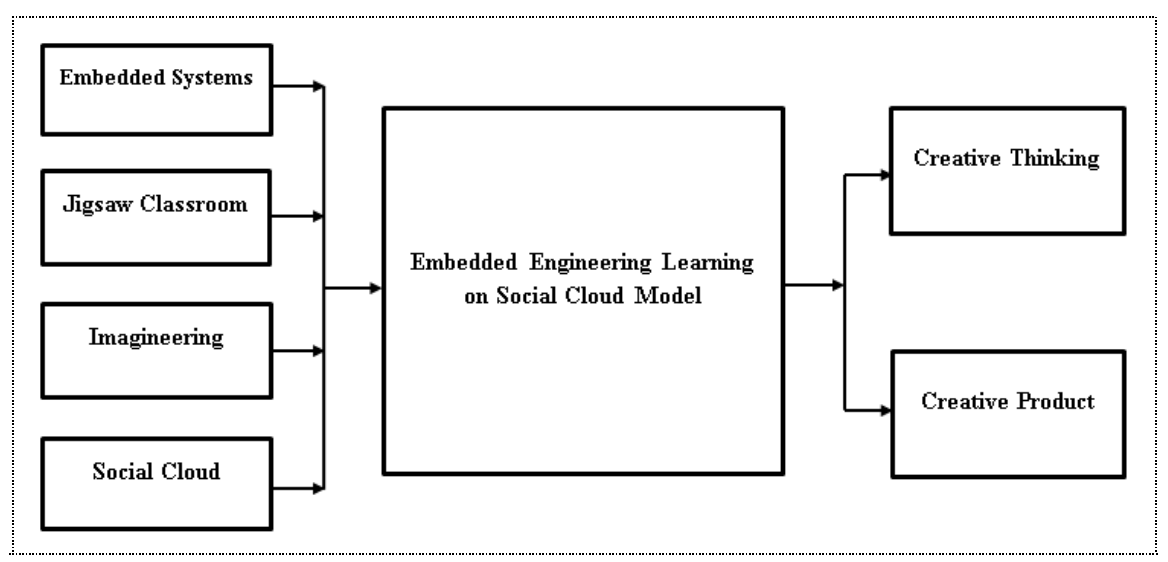

Fig. 1. The Conceptual Framework of an Embedded Engineering Learning on Social Cloud Model to Enhance Creative Thinking and Creative Product. 
Paper-Design of an Embedded Engineering Learning on Social Cloud Model to Enhance Creative Thinking and Creative Product

\section{Scope of the Study}

\subsection{Population}

The study's population included experts in an embedded system information technology and instructional design.

\subsection{Samples:}

Experts were chosen using purposive sampling of individuals with more than 10 years of experience in relevant fields.

\subsection{Variables of the study:}

1. The independent variable was an Embedded Engineering Learning on Social Cloud Model to enhance Creative Thinking and Creative Production.

2. The dependent variable was the evaluation of the model's appropriateness.

\section{$5 \quad$ Research Methodology}

This research had 2 phases.

\subsection{The first phase:}

The first phase was to develop an EEL on SC Model to enhance creative thinking and creative production, with the process as follows:

1. To study, analyze, and synthesize documents and prior research relevant to the elements of Embedded System, Collaborative (Jigsaw), Imagineering, and Social Cloud.

2. To develop an EEL on SC Model to enhance creative thinking and creative production by using data collected from studies and analyses of relevant documents and research.

3. To present an EEL on SC Model to enhance creative thinking and creative production to advisors and experts for consideration by means of in-depth interviews.

4. To create the tools for evaluating the appropriateness of the model.

\subsection{The second phase:}

The second phase of the research was an evaluation of an EEL on SC Model to enhance creative thinking and creative product, with a method as follows: 
1. To present the developed an EEL on SC Model to the seven experts from the fields of embedded system, information technology and instructional design.

2. To improve an EEL on SC Model according with experts' suggestions.

3. To present an EEL on SC Model in the form of a diagram with report.

4. To analyze the results of the evaluation of the model by mean ( ) and standard deviation (S.D.). The evaluation form was built on a 5-point Likert scale: very good, good, moderate, poor and very poor.

\section{$6 \quad$ Results}

The results of this research are divided into 2 parts.

\subsection{The first part:}

An EEL on SC Model to enhance creative thinking and creative production is illustrated in Fig. 2. This model had 7 components with 22 procedures as follows:

Component 1. Jigsaw Group: This component groups students into groups with 36 members with 3 levels of members: skilled, medium, and weak. The Jigsaw Group included 2 steps, which were 1. Home Group and 2. Expert Group.

Component 2. Imagination: In this component, the learners had to create Imagine by brainstorming as it was stated. There were 5 steps of sharing opinions and analyzing the practicality of Imagine that were created by the learners: 1. Study Content (the procedures to study theoretical lessons in each subject), 2. Problem (the starting of a hypothesis), 3. Brainstorm (the thinking of possible solutions), 4. Discussion (the sharing of opinions), and 5. Feasibility (analyzing the possibility of the imaginative solution and whether it is practical to be used).

Component 3. Design: In this component, the learners helped each other design the model by using their imagination. To design, write the storyboard, write the script, and create the model there were 4 steps: 1 . The process of drafting, 2 . The process of writing the story board, 3 . The process of writing the script, and 4 . The process of creating a prototype.

Component 4. Embedded Development: In this component, the learners had to help each other develop the work as it was modeled, beginning with composing the parts according to the model's plan, then writing the program to test the hardware components and whether they can work according to the script. There were 4 steps: 1 . Assembling (composing the components), 2. Coding (writing the program), 3. Compiling (evaluating), and 4. Testing (checking whether it can work properly).

Component 5. Presentation: In this component, learners had to present the work they had created. The lecturers had to construct a competition and vote, which included free commenting to develop better work in the future. This component had 3 steps: 1 . Show (the masterpiece), 2. Contest (let the learners compete with each other), and 3. Suggest (sharing opinions and discussing the works with both the lecturers and the other learners).

Component 6. Improvement: In this component, the learners had to use all of the opinions and comments from lecturers and the other students to fix and develop their group work to be better and to conclude the results by evaluating the advantages, dis- 
advantages, problems, and warnings. This component had 2 steps: 1 . Revision was the process of editing the constructed work and 2. Conclusion was summarizing all of the details about the work.

Component 7 Evaluation: In this component, the lecturers had to assess the creativity the learners had before learning and after the lessons by using the creativity exams. There were 2 steps: 1. Creative Thinking Assessment (the creativity assessment) 2. Creative Production assessment (the work assessment).

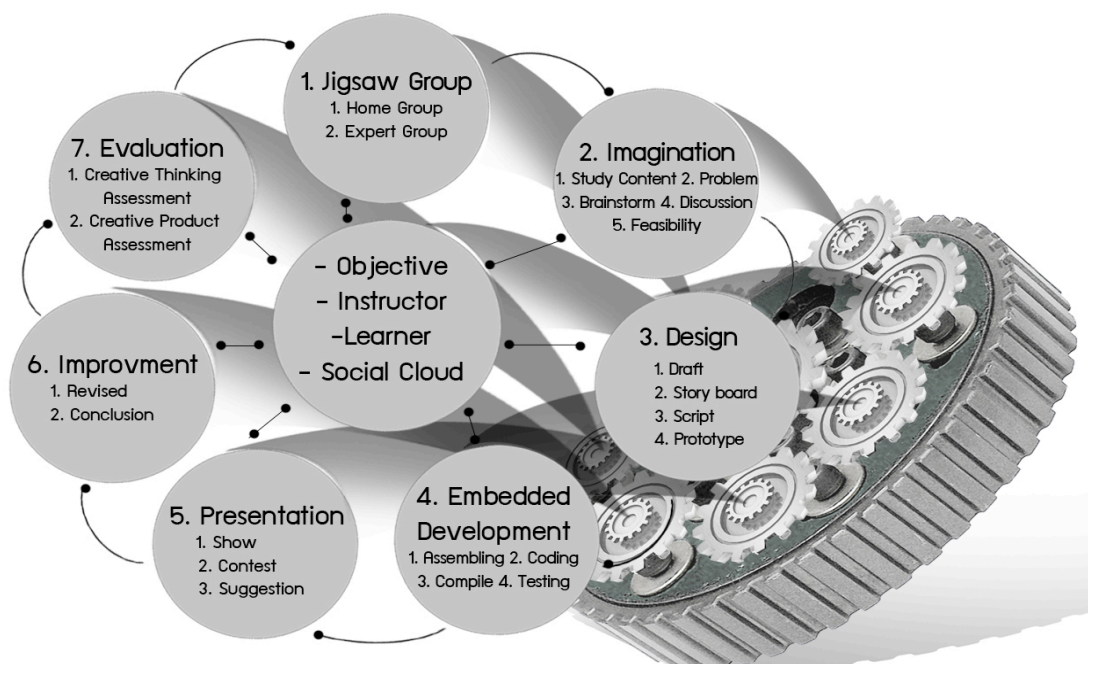

Fig. 2. An Embedded Engineering Learning on Social Cloud Model to Enhance Creative Thinking and Creative Product.

\subsection{The second phase:}

Evaluation of the appropriateness of an EEL on SC Model was constructed by the 7 experts presented in Table 1 .

Table 1 shows that the seven experts agreed with the overall appropriateness in list of an EEL on SC Model that had very good results (mean=4.54, S.D. $=0.49$ ). The "arrangement of the sequences of the components in an Embedded Engineering Learning on Social Cloud Model was suitable and easy to understand" was ranked as very good $($ mean $=4.86$, S.D. $=0.38)$. The appropriateness of the sequences of the model's components that were clear and continuous were ranked as very good (mean $=4.71$, S.D. = 0.49). An Embedded Engineering Learning on Social Cloud Model had the possibility to develop the practical system was ranked as very good (mean $=4.71$, S.D. $=0.49$ ), and The principles of the system used as the base to synthesize an Embedded Engineering Learning on Social Cloud Model" was ranked as very good (mean $=4$. 64, S.D. $=0.46)$. 
Paper-Design of an Embedded Engineering Learning on Social Cloud Model to Enhance Creative Thinking and Creative Product

Table 1. Appropriateness Evaluation of an Embedded Engineering Learning on Social Cloud model to enhance Creative Thinking and Creative Product.

\begin{tabular}{|c|c|c|c|}
\hline \multirow[b]{2}{*}{ Evaluation Lists } & \multicolumn{2}{|c|}{ Results } & \multirow{2}{*}{$\begin{array}{l}\text { Appropriateness } \\
\text { Level }\end{array}$} \\
\hline & $\overline{\mathrm{X}}$ & S.D. & \\
\hline $\begin{array}{l}\text { 1. The principles of the system that were used as the base to } \\
\text { synthesize an Embedded Engineering Learning on Social Cloud } \\
\text { Model }\end{array}$ & 4.64 & 0.46 & Very Good \\
\hline $\begin{array}{l}\text { 2. The components of the model were related an Embedded } \\
\text { Engineering Learning on Social Cloud Model }\end{array}$ & 4.61 & 0.49 & Very Good \\
\hline $\begin{array}{l}\text { 3. The sequences of the model's components that is clear and } \\
\text { continuous }\end{array}$ & 4.71 & 0.49 & Very Good \\
\hline 4. The relations of each component towards the others & 4.57 & 0.53 & Very Good \\
\hline $\begin{array}{l}\text { 5. The arrangement of the sequences of the components in an } \\
\text { Embedded Engineering Learning on Social Cloud Model was } \\
\text { suitable and easy to understand }\end{array}$ & 4.86 & 0.38 & Very Good \\
\hline $\begin{array}{l}\text { 6. The overall of the components of an Embedded Engineering } \\
\text { Learning on Social Cloud Model was complete as it can satisfy, } \\
\text { the needs and accurate to the purposes of the research }\end{array}$ & 4.57 & 0.53 & Very Good \\
\hline $\begin{array}{l}\text { 7. An Embedded Engineering Learning on Social Cloud Model } \\
\text { that to developed a suitable of Creative Thinking }\end{array}$ & 4.57 & 0.53 & Very Good \\
\hline $\begin{array}{l}\text { 8. An Embedded Engineering Learning on Social Cloud that to } \\
\text { developed a suitable of Creative Product }\end{array}$ & 4.57 & 0.53 & Very Good \\
\hline $\begin{array}{l}\text { 9. An Embedded Engineering Learning on Social Cloud Model } \\
\text { had possibility utilization to develop the practical system }\end{array}$ & 4.71 & 0.49 & Very Good \\
\hline Summary & 4.54 & 0.49 & Very Good \\
\hline
\end{tabular}

\section{Discussion}

The results of the evaluation of an EEL on SC Model were related to Julaluk Watthananon's research, which stated that Imagineering learning was effective and beneficial for imagination and creative thinking skills to comply with design development that resulted in creative products. Other research written by Marc Aurel Schnabel and Jeremy J Ham states that the Social Cloud is a tool that supports co-learning environments that increase the efficiency of the learning for learners.

\section{Recommendations for Research Result's Application}

Educational institutions should prepare infrastructures for network systems to access the internet for using online social media and cloud technology.

\section{Acknowledgment}

The researchers would like to thank the Graduate College, King Mongkut's University of Technology North Bangkok, Thailand who supported this research. 


\section{References}

1. Barr, M., \& Massa, A. Programming embedded systems: with C and GNU development tools. O'Reilly Media Inc., 2006.

2. Center for Imagineering Leadership and Renewal "What is Imagineering?," 2011. http://www.bernardfranklinphd.com/2011/04/what-is-imagineering.html. last accessed: April 2016.

3. Chard, K., Bubendorfer, K., Caton, S., \& Rana, O. F. "Social cloud computing: A vision for socially motivated resource sharing," IEEE Transactions on Services Computing, vol.5(4), pp. 551-563, 2012. https://doi.org/10.1109/TSC.2011.39

4. Dictionarist. "Imagineering," (2011).http://www.dictionarist.com/Imagineering. last accessed: April 2016

5. Haas, C., Caton, S., Chard, K., \& Weinhardt, C. "Co-operative infrastructures: An economic model for providing infrastructures for social cloud computing," in System Sciences (HICSS), 2013 46th Hawaii International Conference on. IEEE, 2013, pp.729-738. https://doi.org/10.1109/hicss.2013.147

6. Heath, S. Embedded systems design. Newnes, 2002.

7. Production "What is Imagineering?," 2014. http://www.imagineerproductions.co.uk/res ources/0000/1560/Imagineer Productions Impact 2009 2014 long version FINAL.pdf . last accessed: April 2016.

8. Office of the Prime Minister. Office of the national economic and Social Development Board. "THE ELEVENTH NATIONAL ECONOMIC AND SOCIAL DEVELOPMENT PLAN (2012-2016)," Bangkok, Thailand, 2012. http://www.nesdb.go.th. last accessed: April 2016.

9. Olfa Kanoun. "Chair for Measurement and Sensor Technology Embedded Systems," 2016. https://www.tu-chemnitz.de/studium/studiengaenge/flyer/ embedded_ systems_eng.pdf. last accessed: April 2016.

10. Parab, J., Shinde, S. A., Shelake, V. G., Kamat, R. K., \& Naik, G. M. Practical aspects of embedded system design using microcontrollers. Springer Science \& Business Media. 2008. https://doi.org/10.1007/978-1-4020-8393-8

11. Schnabel, M. A., \& Ham, J. J. "The Social Network Learning Cloud: Architectural Education for the 21st Century," International Journal of Architectural Computing, vol.12(3), pp. 225-241, 2014. https://doi.org/10.1260/1478-0771.12.3.225

12. SIPA. "SIPA Reports results of a survey software market and Software Services Thailand Year 2014," 2012. http://www.sipa.or.th/th/news/2007 last accessed: April 2016.

13. Sonawane, H., Gupta, D., \& Jadhav, A. "Social Cloud Computing Using Social Network," IOSR Journals (IOSR Journal of Computer Engineering), vol. 1(16), pp. 1518.

14. Thailand's, I. C. T. Policy Framework BE 2554-2563. Ministry of Information and Communication Technology, 2000.

15. Vahid, F., \& Givargis, T. Embedded system design: a unified hardware/software introduction vol. 4, New York, NY: John Wiley \& Sons, 2002.

16. Watthananon, J. "A Comparison of the Effectiveness of STEM Learning and Imagineering Learning by Undergraduate Student in Computer Science," International Journal of the Computer, the Internet and Management vol. 23(1) pp. 45-52, 2015.

17. Wright, A. The Imagineering Field Guide to Disneyland: An Imagineer's-eye Tour. Disney editions, 2008. 
Paper-Design of an Embedded Engineering Learning on Social Cloud Model to Enhance Creative Thinking and Creative Product

\section{Authors}

Sathaporn Yoosomboon is $\mathrm{PhD}$. Student division of Information and Communication Technology for Education, Faculty of Technical Education, King Mongkut's University of Technology North Bangkok (KMUTNB), Thailand, 10800 (e-mail: sataporn007@hotmail.com).

Pallop Piriyasurawong is an Assistant Professor at Division of Information and Communication Technology for Education, Faculty of Technical Education, King Mongkut's University of Technology North Bangkok (KMUTNB), Bangkok, Thailand, 10800 (e-mail: palloppi@gmail.com).

Submitted 04 June, 2016. Published as resubmitted by the authors 23 July 2016. 